\title{
Global impact of foodborne diseases on health
}

\author{
${ }^{1,{ }^{*}}$ Mansour, A.A.A., ${ }^{1}$ Gupta, N.B. and ${ }^{2}$ Gupta, S.C. \\ ${ }^{1}$ Department of Public Health, Shalom Institute of Health and Allied Sciences, SHUATS, Allahabad, India \\ ${ }^{2}$ Department of Industrial Microbiology, Jacob Institute of Biotechnology and Bioengineering, SHUATS, \\ Allahabad, India
}

\section{Article history:}

Received: 12 April 2021

Received in revised form: 25

May 2021

Accepted: 31 July 2021

Available Online: 7

November 2021

Keywords:

Food,

Diseases,

Pathogens,

Awareness,

Education

DOI:

https://doi.org/10.26656/fr.2017.5(6).255

\begin{abstract}
The occurrence of foodborne diseases (FBD) has increased in the last decade as a result of negligence for hygiene. Prevalence of FBD due to lack of education, insufficient health services result in the spread of disease on a larger scale. Personal hygiene, as well as local cleanliness, is the most important aspect of the overall health community. Pandemic like COVID is due to lack of personal hygiene as well as health education. The data published by global bodies like World Health Organization (WHO) indicates that the FBD should be controlled by increasing awareness related to personal hygiene and health education. This article reviewed the global occurrence of FBD, preventive measures and solutions for an overall healthy community. The aim of this review is to analyse reports related to foodborne diseases over the globe and suggest guidelines for community health. The scope of this review is in food safety and quality - microbiological and chemical in Food research Journal. Reviews, reports, research data related to foodborne diseases have been analysed and future solutions for building a better health community have been suggested. A total of 74 references including research articles, reviews, press notes, government sites related to foodborne diseases over the globe have been reviewed and data collection has been analysed to suggest better health community guidelines. All the references showed that the occurrence of foodborne diseases are increasing day by day and thus control measure policies have to be implemented worldwide. These include strict government policies, education of food vendors, strict action against those who are not following it, educating the importance of personal as well as community hygiene. These results will surely help to build a better healthy community in future. The data showed that foodborne disease is affecting many populations at any age each year leading to morbidity and mortality. The disease is caused by bacteria, viruses, parasites and fungi. The common symptoms are diarrhoea, vomiting, fever and abdominal pain. Awareness and education related to community health should be spread using advertisements, social media, newspapers, news channels to lower the incidence of foodborne diseases.
\end{abstract}

\section{Introduction}

Foodborne diseases (FBD) over the world have been increasing day by day. Health education, awareness related to foodborne diseases has not been spread through education. The food vendors, food processing authorities do not have enough knowledge about the reasons behind foodborne diseases and overlooking just a minute error can cause health hazards on a larger scale.

Foodborne diseases (FBD) over the world have been increasing day by day. Food poisoning due to unhygienic conditions while handling food causes increase in food borne diseases worldwide. Food spoilage is caused by microorganisms which includes bacteria, yeast and mould. These microorganisms produce harmful toxins or chemicals which alters the characteristics of the food items and leads to spoilage. Upon consumption of these food items, illness like food poisoning, dysentery and other food - borne infections are caused. These organisms may be pathogenic or spoilage types. The pathogenic organisms and toxin - producing types give rise to food poisoning and food - borne infections. The spoilage type may not cause infection but cause spoilage of foodstuffs. Due to food poisoning, mortality rate increases as well as it hampers socioeconomic status of the country. India has increasing cases of FBD yearly as 
awareness related primary education about food hygiene is scarce. The reason for spread of these FBD are may be due to unawareness of health education and knowledge about foodborne diseases. Even primary education related to personal hygiene as well as social cleanliness may be the supplementary causes of spread of FBD. With the pandemic the country hitting hard, personal and social hygiene is also one of the precautions to be taken to prevent further human loss. This article reviews the global occurrence of FBD, preventive measures and solutions for an overall healthy community. The aim of this review is to analyse reports related to foodborne diseases over the globe and suggest guidelines for community health.

\section{Materials and methods}

Data from 74 research papers including reviews, newspapers, government websites, research articles were thoroughly analysed to indicate the necessity of better community health guidelines. The data has been taken from various recent papers which ensures that the number of foodborne diseases cases is continuously increasing day by day. With the aim of suggesting guidelines for minimizing the foodborne disease cases around the globe through WHO sites, International cases, and cases from India research papers. The data was clearly described in tables and also described in the text and was reproducible. The data has been taken from authentic sources and standard methods were used. These methods include the compilation of survey, questionnaire data and analysing it using standard statistical software. This results in verified, organized and compiled data.

\section{Data collected by global organizations for foodborne pathogen infections}

WHO (World Health Organization, 2015a) has reported in the South East Asia region more than half of the people around the globe are infected and die from typhoid fever or hepatitis A. Diarrhoeal diseases are responsible for the majority of deaths which is caused due to Norovirus, Non-typhoidal Salmonella, pathogenic E. coli. Every year, more than 150 million people fall ill out of which 175000 dies, including 60 million children less than 5 years fall ill out of which 50000 dies. Foodborne diseases can be prevented if food safety is maintained. According to World Health Organization (2015a), FBD has a social as well as an economic impact on society. Mortality and morbidity rates are increasing day by day and the cause of these hazardous effects is unknown. The information related to the burden of FBD can help food safety control. Bacteria, fungi, viruses and other microbial and chemical agents have been identified to cause around 4 million deaths in 2010. The most prevalent region for FBD burden was found to be Africa followed by Southeast Asia. The children under 5 years of age living in low-income subregions of the world have more disease burden. Information related to foodborne diseases should be provided on a national level to set worldwide informed policies that can help safety policies to be implemented worldwide.

Kirk et al. (2015) have reviewed and estimated global estimates for foodborne diseases which results in morbidity and mortality. Global and regional data of several foodborne illnesses, deaths, and DisabilityAdjusted Life Years (DALYs), for all diseases, were analysed. Studies included diarrhoeal pathogens, Mycobacterium bovis infections and non-typhoidal Salmonella enterica infections. Foodborne diseases which result in diarrheal disease are more prominent in children. The focus should be on food safety interventions in preventing foodborne diseases, particularly in low- and middle-income populations. Hanson et al. (2012) has analysed global mortality due to potentially foodborne diseases using vital registration data. As foodborne diseases (FBD) consist of a large part of the global mortality burden, data collection and analysis is important to prevent future incidences. The true extent of these diseases is unknown and thus multiple regression model was used. Non-health variables, as well as traditional health indicators, were used to predict FBD mortality at the country level as per World Health Organization classifications AmrA, AmrB, EurA and EurB. Non-health variables like percent irrigated land, average calorie supply from animal products, meat production in metric tons, adult literacy rate, adult HIV/AIDS prevalence and percent of deaths under age 5 caused by diarrheal disease were used and were found to be more robust predictors of mortality than health variables as well as remained significant when adding additional health variables into the analysis and thus may be a powerful tool in the effort to estimate the global mortality burden of FBD. Kuchenmuller et al. (2009) has reported that WHO (World Health Organization, 2015b) aims to initiate to fill the data gap to estimate the global burden of foodborne diseases. This is in response to increasing global interest in health information. Unsafe food consumption causes illness and deaths and it also hampers socio-economic development throughout the world. The burden and cost of foodborne diseases caused due to bacterial, viral and parasites and food contaminated by chemicals is not known. There should be a joint effort to assess the foodborne disease burden from all causes on a global scale. WHO Initiative has assembled a group of stakeholders that will share and support vision, intended objectives and outcomes. European Centre for Disease Prevention and Control 
(ECDC) has started a study on the burden of at least 18 foodborne diseases occurring in nearly 30 countries.

Chlebicz and Slizewska (2018) have reviewed symptoms, factors affecting campylobacteriosis, salmonellosis, yersiniosis, and listeriosis pathogenesis. These zoonoses are transmitted from animals to humans, causing a threat to human life all over the world. WHO noted 600 million cases of diseases caused by contaminated food in 2010 . These zoonoses mostly grow in poultry, cattle, and swine as well as in wild animals, pets, fish, and rodents. Faeces of these animals may contain pathogens that can reside on vegetables and fruits. Pathogenic bacteria produce biofilm covering the surfaces of machines and equipment and penetrate food production areas. Improper or careless food processing leads to pathogenic entry into food leads to food poisoning. Symptoms may be mild, flu-like, but complications can be fatal. Zheng and Shen (2018) have reported about the Faecal Source Tracking (FST) as an effective tool to identify the sources of faecal pollution. As faecal pollution in food and water is the major cause of disease outbreaks, accurate identification of this faecal pollution is necessary. A significant number of novel genetic markers of faecal indicator bacteria (FIB) suitable for FST have been identified using advanced DNA technologies and bioinformatics. Most of the genetic markers were only evaluated in laboratory settings and thus there is a need for further assessment of monitoring food and water safety using these techniques. Hoffmann et al. (2017) has reported a study related to estimates for 11 major Foodborne Diseases in each of 14 world subregions. For preventing illness, understanding different exposure routes of food are critical. WHO has used Cooke's Classical Model to which has produced judgements of 73 international experts. In the American and African subregions, for non-typhoidal salmonellosis, eggs and poultry meat were more responsible than pork while the importance of these three food sources was quite similar in European and Western Pacific subregions. These estimates will provide the best relation between FBDs and specific foods in different parts of the world, helping to make policies to control FBDs. Integrated Disease Surveillance Programme (IDSP) receives disease outbreak reports from all states. These reports are analysed and policies are implemented to strengthen the disease surveillance system for epidemicprone diseases and to respond to outbreaks in future. From 2008, reports of outbreaks increased continuously over the years till 2017. Major diseases include Acute Diarrhoeal Diseases, Food Poisoning and Measles. The weekly reporting of outbreaks is important as it indicates the shift in pattern in the outbreak reporting in time. Data analysis, action and feedback are undertaken by the respective reporting districts/states.

\section{Global cases of foodborne pathogens}

Gupta (2017) have reviewed causes and symptom due to foodborne diseases. Most of the bacterial pathogens include Salmonella, Staphylococcus, Clostridium perfringens, Escherichia coli or Bacillus cereus which results in gastroenteritis, fever and weakness, the fungus may affect crops of cereals, millets, and legumes during storage releasing aflatoxins. These diseases may happen due to inherent components of food or introduced into food from outside. Prevention can be done by keenly observing food items and maintaining the cook's hygiene in the kitchen. Alimi (2016) has reviewed risk factors in street food trade in developing countries and have recommended safety measures to provide a global baseline to ensure safe food practices. Though street food provides a ready meal at relatively low rates, risks to the health and safety of practitioners increase drastically. The entire chain of street food business should be analysed at critical control points from good agricultural practices through hazard analysis, to good hygiene practices by farmers, vendors and consumers which will reduce risks in street food consumption on a holistic level. Addis and Sisay (2015) have reviewed different types of foodborne diseases and their occurrence. These diseases are caused by the consumption of contaminated foods or water. Out of two classes of these diseases are by intoxication which is caused by ingestion of the toxin produced by pathogens, while the infection is caused by ingestion of food containing viable pathogens. Intoxication results in rapid onset of illness and people become very sick. Infection is mostly caused by bacteria like Clostridium, E. coli, Salmonella and Staphylococci. These intoxication or infection results in diarrhoea, vomiting, abdominal cramps, headache and nausea. These illnesses can be prevented by food safety control in place through food production, processing and distribution keeping food clean, separation of raw and cooked, and cooking thoroughly, keeping food at a safe temperature and using safe water and raw materials. Strict hygienic control measures to improve the hygienic conditions during manufacturing, handling, storage and commercialization of foods should be implemented. Lund et al. (2011) have reviewed the occurrence of infection by foodborne pathogens in these groups of people and measures to prevent infection. The nature and use of low microbial diets to reduce the risk of foodborne disease in immunocompromised patients are very variable. Diets for vulnerable people in care should exclude higher risk foods, and vulnerable people in the community should receive clear advice about food safety, in particular avoidance of higher-risk foods and substitution of safer, nutritious foods. 
Newell et al. (2010) has reviewed data on food safety is insufficient to conclude future predictions related to foodborne diseases impact on developed as well as developing countries. The microbiological safety of food is heavily influenced by multiple factors from farmers to consumers. Food safety standards should be vigilantly monitored as well as food security, obesity and climate change, competition for resources in the future should also be considered. Food is a carrier of pathogens (bacteria, viruses/prions and parasites) that colonise in a new host and cause disease. Food pathogens like Salmonella spp., Campylobacter, Shigella and Vibrio spp., methicillin-resistant Staphylococcus aureus, E. coli and Enterococci can evolve to create new public health challenges like antimicrobial resistance.

Antimicrobial resistance is caused when pathogenic organisms evolve their mechanism to resist standard antibiotics. Overuse of antibiotics has resulted in the development of resistance mechanisms by most pathogens. The most well-known example is MethicillinResistant Staphylococcus aureus which occurred due to overuse of methicillin antibiotic in clinical studies. This resulted in the ineffectiveness of methicillin treatment in the same patients after they had developed infection again. Due to MRSA, the body does not react to antibiotics and may result in death as treatment no longer works. Similarly, for all the food pathogen infections of E. coli and Enterococci, initial treatment with broadspectrum antibiotics results in antibiotic resistance development and becomes ineffective in long term treatment. Thus, has been a major concern with antibiotics in the last decades.

Zoonotic pathogens are also emerging continuously. Norovirus, Hepatitis A, rotaviruses and newly emerging viruses such as SARS are also evolving. Monitoring of parasites like Ascaris, Cryptosporidia and Trichinella is done but their connection in foods, livestock and wildlife and epidemiology through the food chain is not very well known. To monitor changing trends in these diseases and detection of emerging pathogens, the collaboration between public health, veterinary and food safety experts should be established.

Pigott (2008) have reviewed outbreaks of foodborne illness in the US as pre-packaged and processed foods consumption is high and food is imported from nonindustrialized nations where quality controls and hygienic practices are not up to the mark. Contaminated food and water cause foodborne illness syndromes and clinicians should be alert to reduce potential deaths. Greig et al. (2007) have reported data collected by the Committee on Control of Foodborne Illnesses of the International Association for Food Protection and its evaluation on worker-associated outbreaks. Foodborne disease outbreaks due to food workers are not diminishing. From 1927 to 2006, 816 reports with 80,682 cases were collected from the United States, Canada, Europe, and Australia, Outbreaks were caused by norovirus, Salmonella enterica, hepatitis A virus, Staphylococcus aureus, Shigella spp., Streptococcus and parasites Cyclospora, Giardia and Cryptosporidium. Norovirus and nontyphoidal Salmonella outbreaks are increasing because of more frequent hand contact during preparation and serving. Van De Venter (2000) have analysed the emergence of new food-borne pathogens or chemical in nature. The most prominent emerging foodborne pathogens are bacteria, viruses and protozoa while mycotoxins, pesticide residues, veterinary drugs and unconventional agents such as prion and environmental contaminants can cause a hazardous effect on human health. These changes are due to development, urbanization and new lifestyles, cuts in health systems, existing knowledge, beliefs and practices, demographic changes, travel and migration, trade-in food, animal feed and animals and poverty and pollution. These problems cannot be solved in isolation but need a unified and joint approach by all countries. Appropriate international organizations need to draw a plan of action to encourage and assist countries to develop efficient food control systems. Indicating the minimum or basic parameters or requirements for such a purpose should also be done. These systems need to use assessment, management and communication for risk analysis. Focus on the hazards and foods which are harmful to public health should be given and preventive control of these risks should be a primary concern.

Zweifel and Stephan (2012) have surveyed the literature on Salmonella-related outbreaks caused by spices and herbs in Europe and North America. Due to high desiccation tolerance, Salmonella can survive for a longer time in spices and dried herbs and if untreated spices and herbs are used in heat-treated foods or for seasoning of ready-to-eat products including plantderived food, Salmonella in this way might pose a threat to consumers. Podolak et al. (2010) has reviewed sources and risk factors for contamination, survival, persistence, and heat resistance of Salmonella in low-moisture foods. Low-water-activity foods like peanut butter, infant formula, chocolate, cereal products, dried milk do not support the growth of Salmonella but crosscontamination might occur after sterilization which might increase significant food safety risks. This may happen due to poor sanitation practices, poor equipment design, and poor ingredient control. Simjee (2007) reports a multi-state outbreak of Salmonella serotype Agona present in a toasted oat cereal in 1998. To ensure a safe food supply, global cooperation in food pathogen research, monitoring and education are necessary. To 
control and reduce foodborne diseases, efforts should be taken to educate food processing personnel.

Mahato et al. (2019) have reviewed the sources of contamination, occurrence, detection techniques of mycotoxin, with management strategies to ensure food safety. Aspergillus species produce highly toxic aflatoxins, carcinogenic when contaminates food sources like groundnuts, millet, sesame seeds, maize, wheat, rice, fig, spices and cocoa can lead to serious health problems. Commercial products like peanut butter, cooking oil and cosmetics even after processing can be contaminated with aflatoxins. At low concentration, aflatoxins are hazardous for human and livestock, thus feasible, sensitive and robust analytical methods for identification and quantification is a necessity. Kumar et al. (2017) has reviewed the need of developing suitable methods for aflatoxin quantification, precise detection and control to ensure the safety of consumers' health. Spreading knowledge related to aflatoxin sources, production, detection and control measures of aflatoxins will help to ensure food and feed safety. Russell et al. (2017) has reported an increase in severe mycoses in immunosuppressed individuals due to filamentous Aspergillus fumigatus. Aspergillus, Fusarium and Mucor can cause severe diseases and thus it is necessary to increase awareness of the connection between food and these fungal pathogens. Wu et al. (2014) has reviewed adverse human health impacts associated with mycotoxins. Most agriculturally important mycotoxins known as aflatoxins colonise food crops and can liver cancer, child growth impairment, renal diseases and acute toxicoses. Cheng et al. (2009) investigated an outbreak of intestinal infection due to Rhizopus microspores in 12 patients on treatment for haematological malignancies. Consumption of commercially packaged ready-to-eat food items before 2 weeks was found to be a significant risk factor for the development of intestinal zygomycosis. Pitt (2000) has reviewed types of mycotoxins causing allergic responses, immunosuppression and cancer. There are five types of mycotoxins - aflatoxins, ochratoxin A, fumonisins, trichothecenes and zearalenone. All these mycotoxins can result in human mortality and reports of them are underestimated.

Pires et al. (2009) has reported efforts to prevent and control foodborne zoonoses. Zoonoses are diseases that humans can get transmitted from animals and thus finding the source of infection is of utmost importance. To address public health questions, nomenclature and describing the various approaches for human illness, source attribution is useful. Hassan and Honua (2018) have studied bacterial contamination by food handlers working in restaurants of Wad Madani city. Khan et al.
(2018) has designed a study to know the hygiene practices of street food vendors in Barisal city, Bangladesh. Zahoor et al. (2018) have studied microbial evaluation and safety assessment of most commonly consumed traditional foods sold in various markets of Faisalabad, Pakistan. Assefa and Bihon (2018) have reviewed to estimate the prevalence of Escherichia coli in different foods of animal origin in Ethiopia. Allam et al. (2016) have conducted a study to assess hand contamination among food handlers working in Menoufia University and Shebin Al-Kom Educational hospital kitchens. Assefa et al. (2015) has studied to assess the bacterial hand contamination and associated factors among food handlers working in the student cafeterias of Jimma University main campus. Okareh and Erhahon (2015) have conducted a study to assess microbial contamination of food and hand-swabs samples of 60 food vendors from public secondary schools from Oredo (OD), Egor (EG) and Ikpoba-Oha (IK) in Benin City. Kadariya et al. (2014) have carried out Staphylococcal food-borne disease (SFD) outbreak investigations in the United States. Lee et al. (2014) have isolated a Mucor circinelloides strain from a yoghurt container. Lambrechts et al. (2014) have studied the efficacy of handwashing practices and sanitation before commencing work among food handlers in the food industry in Gauteng, South Africa. Nyenje et al. (2012) have studied to assess the microbiological quality of various ready-to-eat foods sold in Alice, South Africa. Sudershan et al. (2008) have analysed deaths among children due to foodborne diseases.

\section{Foodborne disease cases from India}

Bisht et al. (2021) have analysed the distribution of foodborne outbreaks in India in 2008-2018 using GAM and ARIMA models. Parry (2018) has summarised food poisoning cases in India in 2017. Integrated Disease Surveillance Programme (IDSP) (2019) confirms that milk is the most common contaminated product in food poisoning which is the second most common cause of infectious disease outbreaks. Some incidences of food poisoning include Mumbai-bound Tejas Express from Goa in October 2017, suspected food poisoning in Jharkhand involved four individuals dying by consumption of morning contaminated meal. The trend of food poisoning is consistent since 2008 (50 cases) and is increasing on yearly basis (2017 - 242 cases) as observed by A. C. Dhariwal (Director of the National Centre for Disease Control (NCDC) (2017). Bhat et al. (2008) has surveyed food poisoning in a few villages of the Deccan plateau in India which happened due to maize and sorghum crops in 1995. Kumar et al. (2001) has reviewed that Staphylococcal food poisoning is a typical foodborne infection in India mostly due to 
consumption of dairy products (Das and Khanna 1995). Recently, in 1996, in Bhiwani, Mumbai, India, the outbreak of food poisoning due to the consumption of pedhas was reported (Jaspal et al., 1996a). Sehgal et al. (2008) have done a 10-year epidemiological survey of $E$. coli $\mathrm{O} 157$ in different regions of India. Keisam et al. (2019) has reported incidences of enteric bacterial pathogens in the traditional fermented foods from the Northeast region of India. Saravanan et al. (2016) have surveyed in order to gain knowledge, attitude and awareness of food safety among food vendors in Tamil Nadu. Sudershan et al. (2014) have done a pilot study to investigate the food poisoning cases, undertaken by the Ronald Ross Institute of Tropical Diseases in Hyderabad. Mazumdar and Goswami (2016) have studied to determine the food safety aspects and practices of street food vendors in Guwahati city. According to the National Institute of Cholera and Enteric Diseases, Kolkata, India reports by Chowdhury et al. (2012) Salmonella enterica serovar Weltevreden and Vibrio fluvialis have been identified as etiological agents of a foodborne gastroenteritis outbreak associated with the consumption of mutton ghogni during an Iftar party on July 30th, 2012 in North Dumdum, West Bengal, India. Singh et al. (2018) conducted a study on 200 street food vendors in the New Okhla Industrial Development Authority (NOIDA) of Gautambudh Nagar district of Uttar Pradesh. Thakur et al. (2013) have done a study to assess food safety and hygiene practices amongst street food vendors in Delhi, India. Kristkova et al. (2017) have studied the first assessment of economic impacts of food safety using an economy-wide (CGE) model in India. Khare et al. (2018) have reported outbreaks of foodborne diseases due to microbiological and environmental contaminants in India. Vemula et al. (2012) has reviewed the nature and extent of foodborne diseases in India due to chemical and microbial agents. Tambekar et al. (2008) have reviewed the safety of street vendor food for human consumption and as potential sources of bacterial pathogens. Ghatak and Chatterjee (2018) have studied with the objective to inspect the food safety and hygiene practices of Chinese street vendors of Kolkata. Singh et al. (2016) have studied to assess the impact of a health education intervention on food safety and hygiene of street vendors. Kharel et al. (2016) have analysed microbiological pathogenic bacteria in ethnic foods of both Gangtok and Nainital in the Indian Himalayas, India. Sabbithi et al. (2014) have studied to analyse the microbiological quality of salads served along with street foods of Hyderabad. Kharel and Tamang (2010) have reviewed reports related to street vendors in India. Kumar et al. (2019) have reviewed different foodborne pathogens and their sources. Jasmine al. (2018) have studied to assess the awareness and practice of food safety at home among the rural population in the Kancheepuram district of Tamil Nadu state. Pal (2014) have reviewed fungal spoilage dairy products in India. Urmimala and Sukanya (2017) has studied to review the "Hygienic Practices of Food Handlers in India" which showed that personal hygiene of the food handlers was found to be below standards and there is the necessity of giving food hygiene education to food handlers to inculcate the practices of good personal hygiene. Vyas and Pandya (2019) have investigated the foodborne outbreak affecting 156 girl students studying in standard VII to XII of low literacy girl high school run by the tribal sub-plan office, Rajpipala Narmada District, India. Students suffered from acute gastroenteritis, vomiting, headache, mild abdominal pain due to staphylococcal infection through milk.

According to Integrated Disease Surveillance Program from $9^{\text {th }}$ to $15^{\text {th }}$ September 2019, food poisoning in Chickaballapura, Karnataka was reported. According to a study reported by Times of India (2019), Food-borne diseases cost India \$15 billion a year. Jain et al. (2015) have reported the occurrence of Salmonella enterica serovar Weltevreden associated foodborne gastroenteritis outbreak in Pune, Maharashtra, India. Kunwar et al. (2013) have reported an outbreak of 53 cases of food poisoning from a Military establishment on 29 May 2011 of food poisoning in few hours. Pandya (2019) have investigated the foodborne outbreak affecting 156 girl students studying in standard VII to XII of low literacy girl high school run by the tribal sub-plan office, Rajpipala Narmada District, India. National Centre for Disease Control (2017) monthly newsletter has reported that new foodborne diseases due to emerging and reemerging pathogens have been identified. Also, this has been associated with social and behavioural factors, environmental hazards, scientific and technological progress and demographic changes. But data on foodborne illnesses are scarce to create new policies related to food safety in India. Efforts to enhance foodborne disease surveillance should be rolled out. Robust foodborne disease surveillance combined with rapid quality outbreak investigations are essential to strengthening food safety. This will provide essential data to understand the source of foodborne illness, the types of food vehicles responsible, sources and routes of food contamination, including gaps in food production, distribution, preparation, and storage practices.

\section{Suggestions to control foodborne disease occurrence}

Odeyemi (2016) has reported how and why collaborative effort between governments of developing 
countries, policymakers, researchers and the general public is necessary to reduce foodborne diseases incidences. It is known that foodborne diseases in developing countries have a large impact on economic and public health. Detection of foodborne pathogens using rapid methods for detection is required. To prevent the transmission of foodborne diseases and spread awareness about these diseases, there should be a collaboration between researchers in developing countries and researchers in developed countries. Scott (2003) has reported that public hygiene education is a key factor in improving food safety practices in the home. Following better farm practices, food processing regulations have resulted in reducing the levels of food pathogens. In near future, the last line of defence against foodborne pathogens will be housed. Food hygiene education benefits as a reduction of foodborne illness at home also help to build local and national economies of foodservice sectors. Schlundt (2002) has analysed data to show the developments of the major foodborne pathogens which has increased over the last decade. Though there are developments in food production and new control philosophies for the prevention of foodborne disease, a number of problems are high levels of foodborne microbiological diseases. A new model for the integration of research data, food-control monitoring, epidemiological investigations and disease surveillance will help with a new view to manage and lower foodborne risk. Direct interaction between surveillance and risk analysis systems can improve foodborne disease prevention. Food safety is one of WHO's top 11 priorities and more systematic and aggressive steps should be taken to reduce the risk of microbiological foodborne diseases. Tauxe (1997) have reported the emergence of new pathogens which are spreading worldwide. There is a need for improved surveillance combining rapid subtyping methods, cluster identification, and collaborative epidemiologic investigation which can identify and stop large outbreaks.

\section{Results and discussion}

The data were thoroughly analysed and all the data indicates the necessity of improving awareness related to food safety. As foodborne pathogen cases are increasing day by day, people should be made aware of the ill effects of foodborne diseases on a larger scale using health awareness surveys, advertisements, questionnaires, health education in primary schools. This will readily improve the health quality of society.

Through this review, a huge amount of data in recent years related to foodborne diseases has been thoroughly reviewed. The data supports the requirement of hygiene awareness by individuals to minimise the chances of foodborne infections on a global scale. The recommendations given by WHO and other government authorities should be strictly followed by individuals and this will surely decrease the incidences of foodborne infections in near future.

\section{Conclusion}

The review certainly focuses on the ill effects of foodborne diseases and their effect on overall society. The guidelines given by health authorities are helpful to minimise foodborne incidences. Implementation of these guideline measures should be strictly implemented in future so that foodborne disease incidences are minimised. This reviewed data will surely help to form guidelines for a better future health perspective.

\section{Conflict of interest}

The authors declare no conflict of interest.

\section{Acknowledgements}

We would like to thank the Department of Public Health, Shalom Institute of Health and Allied Sciences, Allahabad, SHUATS for their support.

\section{References}

Addis, M. and Sisay, D. (2015). A Review on Major Food Borne Bacterial Illnesses. Journal of Tropical Disease, 3(4), 1000176.

Alimi, B.A. (2016). Risk factors in street food practices in developing countries: A review. Food Science and Human Wellness, 5(3), 141-148. https:// doi.org/10.1016/j.fshw.2016.05.001

Allam, H.K., Al-Batanony, M.A., Seif A.S. and Awad, E.T. (2016). Hand Contamination among Food Handlers. British Microbiology Research Journal, 13 (5), 1-8. https://doi.org/10.9734/BMRJ/2016/24845

Assefa, A. and Bihon, A. (2018). A systematic review and meta-analysis of prevalence of Escherichia coli in foods of animal origin in Ethiopia. Heliyon, 4, e00716.https://doi.org/10.1016/

j.heliyon.2018.e00716

Assefa, T., Tasew, H., Wondafrash B. and Beker, J. (2015). Assessment of bacterial hand contamination and associated factors among food handlers working in the student cafeterias of Jimma University main campus, Jimma, Southwest Ethiopia. Journal of Community Medicine and Health Education, 5, 345. https://doi.org/10.4172/2161-0711.1000345

Bhat, R.V., Shetty, P.H., Rao, P.A. and Rao, V.S. (2008). A Foodborne Disease Outbreak Due to the 
Consumption of Moldy Sorghum and Maize Containing Fumonisin Mycotoxins. Journal of Toxicology: Clinical Toxicology, 35(3), 249-255. https://doi.org/10.3109/15563659709001208

Bisht, A., Kamble, M.P., Choudhary, P., Chaturvedi, K., Kohli, G., Juneja, V.K., Sehgal, S. and Taneja, N.K. (2021). A surveillance of food borne disease outbreaks in India: 2009-2018. Food Control,121, 107630. https://doi.org/10.1016/ j.foodcont.2020.107630

Cheng, V.C.C., Chan, J.F.W., Ngan, A.H.Y., To, K.K.W., Leung, S.Y., Tsoi, H.W., Yam, W.C., Tai, J.W.M., Wong, S.S.Y., Tse, H., Li, I.W.S., Lau, S.K.P., Woo, P.C.Y., Leung, A.Y.H., Lie, A.K.W., Liang, R.H.S., Que, T.L., Ho, P.L. and Yuen, K.Y. (2009). Outbreak of Intestinal Infection Due to Rhizopus microspores. Journal of Clinical Microbiology, 47(9), 2834-2843.https:// doi.org/10.1128/JCM.00908-09

Chlebicz, A. and Slizewska, K. (2018). Campylobacteriosis, Salmonellosis, Yersiniosis, and Listeriosis as Zoonotic Foodborne Diseases: A Review. International Journal of Environmental Research and Public Health, 15(5), 863. https:// doi.org/10.3390/ijerph15050863

Chowdhury, G., Sarkar, A., Pazhani, G.P., Mukhopadhyay, A.K., Bhattacharya M.K. and Ramamurthy, T. (2013). An outbreak of foodborne gastroenteritis caused by dual pathogens, Salmonella enterica serovar Weltevreden and Vibrio fluvialis in Kolkata, India. Foodborne Pathogens and Disease, 10(10), 904-906. https://doi.org/10.1089/ fpd.2013.1491

Ghatak, I. and Chatterjee, S. (2018). Urban street vending practices: an investigation of ethnic food safety knowledge, attitudes, and risks among untrained Chinese vendors in Chinatown, Kolkata. Journal of Ethnic Foods, 5(4), 272e285.

Greig, J.D., Todd, E.C.D., Bartleson, C.A. and Michaels, B.S. (2007). Outbreaks Where Food Workers Have Been Implicated in the Spread of Foodborne Disease. Part 1. Description of the Problem, Methods, and Agents Involved. Journal of Food Protection, 70(7), 1752-1761.https:// doi.org/10.4315/0362-028X-70.7.1752

Gupta, R.K. (2017). Chapter 2 - Foodborne infectious diseases. In Dudeja, P., Gupta, R., Minhas, A.S. (Eds). Food Safety in the 21st Century, Public Health Perspective. $1^{\text {st }}$ ed., p. 13-28. USA: Academic Press. https://doi.org/10.1016/B978-0-12-8017739.00002-9

Hanson, L.A., Zahn, E.A., Wild, S.R., Dopfer, D., Scott, J. and Stein, C. (2012). Estimating global mortality from potentially foodborne diseases: an analysis using vital registration data. Population Health Metrics, 10, 5. https://doi.org/10.1186/1478-7954-10 $-5 \mathrm{a}$

Hassan, S.M. and Honua, M. (2018). The bacterial contamination of food handlers' hands in Wad Madani city restaurants, Sudan. International Journal of Community Medicine and Public Health, 5(4),1270-1273.https://doi.org/10.18203/23946040.ijcmph20181201

Hoffmann, S., Devleesschauwer, B., Aspinall, W., Cooke, R., Corrigan, T., Havelaar, A., Angulo F., Gibb, H., Kirk, M., Lake, R., Speybroeck, N., Torgerson, P., Hald, T. (2017). Attribution of global foodborne disease to specific foods: Findings from a World Health Organization structured expert elicitation. PLoS ONE, 12(9), e0183641. https:// doi.org/10.1371/journal. pone.0183641

Integrated Disease Surveillance Program (IDSP). (2019). 37th Week Outbreak Report. Retrieved from IDSP website: https://idsp.nic.in/WriteReadData/ 1892s/42935830501604991853.pdf

Integrated Disease Surveillance Programme (IDSP). (2018). Ministry of Health and Family Welfare, Government of India, Outbreaks: Integrated Disease Surveillance Programme (IDSP). Retrieved from IDSP website: https://www.idsp.nic.in/index4.php? lang $\% 20=1 \&$ level $=0 \&$ linkid $=403 \&$ lid $=3685$.

Jain, P., Nandy, S., Bharadwaj, R., Niyogi, S.K. and Dutta, S. (2015). Salmonella enterica serovar Weltevreden ST1500 associated foodborne outbreak in Pune, India. Indian Journal of Medical Research, 141(2), 239-241.https://doi.org/10.4103/09715916.155595

Jasmine, V.G.C., Loganathan, F. and Mallika, S.V. (2018). Food safety awareness and food handling practices among rural population of Tamil Nadu. International Journal of Community Medicine and Public Health, 5(4), 1441-1447. https:// doi.org/10.18203/2394-6040.ijcmph20181214

Kadariya, J., Smith, T.C. and Thapaliya, D. (2014). Staphylococcus aureus and Staphylococcal FoodBorne Disease: An Ongoing Challenge in Public Health. BioMed Research International, 2014, 827965. https://doi.org/10.1155/2014/827965

Keisam, S., Tuikhar, N., Ahmed, G. and Jeyaram, K. (2019). Toxigenic and pathogenic potential of enteric bacterial pathogens prevalent in the traditional fermented foods marketed in the Northeast region of India. International Journal of Food Microbiology, 296, 21-30. https://doi.org/10.1016/ j.ijfoodmicro.2019.02.012 
Khan, M.S.I., Sayeed, A., Akter, A., Islam M.A. and Akter, S. (2018). Food safety and hygiene practices of vendors during chain of street food production in Barisal city. Food Safety and Health, 1(1), 57-65.

Khare, S., Tonk, A. and Rawat, A. (2018). Foodborne diseases outbreak in India: A review. International Journal of Food Science and Nutrition, 3(3), 9-10.

Kharel, N. and Tamang, J.P. (2010). Street Foods: Risk and Safety. Journal of Hill Research, 23(1 and 2), 19.

Kharel, N., Palni, U. and Tamang, J.P. (2016). Microbiological assessment of ethnic street foods of the Himalayas. Journal of Ethnic Foods, 3(3), 235 241.https://doi.org/10.1016/j.jef.2016.01.001

Kirk, M.D., Pires, S.M., Black, R.E., Caipo, M., Crump, J.A., Devleesschauwer, B., Dopfer, D., Fazil, A., Fischer-Walker, C.L., Hald, T., Hall, A.J., Keddy, K.H., Lake, R.J., Lanata, C.F., Torgerson, P.R., Havelaar, A.H. and Angulo, F.J. (2015). World Health Organization Estimates of the Global and Regional Disease Burden of 22 Foodborne Bacterial, Protozoal, and Viral Diseases, 2010: A Data Synthesis. PLOS Medicine, 12(12), e1001940. https:// doi.org/10.1371/journal.pmed.1001940

Kristkova, Z.S., Grace, D. and Kuiper, M. (2017). The economics of food safety in India - a rapid assessment. Amsterdam, Netherlands: Wageningen University and Research.

Kuchenmuller, T., Hird, S., Stein, C., Kramarz, P., Nanda, A. and Havelaar, A.H. (2009). Estimating the global burden of food borne diseases - a collaborative effort. Eurosurveillance, 14(18), 19195. https://doi.org/10.2807/ese.14.18.19195-en

Kumar, P., Mahato, D.K., Kamle, M., Mohanta, T.K. and Kang, S.G. (2017). Aflatoxins: A Global Concern for Food Safety, Human Health and Their Management. Frontiers in Microbiology, 7, 2170. https:// doi.org/10.3389/fmicb.2016.02170

Kumar, A., Kumar, M. and Sharma, N. (2019). Indian Based Foodborne Diseases-A Discussion. EC Microbiology, 15(8), 771-776.

Kumar, J.K., Sharma, A.K. and Kulkarni, P.R. (2001). Survey of Indian foods for Staphylococcus aureus. The Indian Veterinary Journal, 78(10), 875-878.

Kunwar, R., Singh, H., Mangla, V. and Hiremath, R. (2013). Outbreak investigation: Salmonella food poisoning. Medical Journal Armed Forces India, 69 (4), 388-391. https://doi.org/10.1016/ j.mjafi.2013.01.005

Lambrechts, A.A., Human, I.S., Doughari, J.H. and Lues, J.F.R. (2014). Bacterial contamination of the hands of food handlers as indicator of hand washing efficacy in some convenient food industries. Pakistan Journal of Medical Sciences, 30(4), 755758.https://doi.org/10.12669/pjms.304.4400

Lee, S.C., Billmyre, R.B., Li, A., Carson, S., Sykes, S.M., Huh, E.Y., Mieczkowski, P., Ko, D.C., Cuomo, C.A. and Heitman, J. (2014). Analysis of a food-borne fungal pathogen outbreak: virulence and genome of a Mucor circinelloides isolate from yogurt. mBio, 5(4), e01390-14. https:// doi.org/10.1128/mBio.01390-14

Lund, B.M. and O'Brien, S.J. (2011). The Occurrence and Prevention of Foodborne Disease in Vulnerable People. Foodborne Pathogens and Disease, 8(9), 961-973. https://doi.org/10.1089/fpd.2011.0860

Mahato, D.K., Lee, K.E., Kamle, M., Devi, S., Dewangan, K.N., Kumar, P. and Kang, S.G. (2019). Aflatoxins in Food and Feed: An Overview on Prevalence, Detection and Control Strategies. Frontiers in Microbiology, 10, 2266. https:// doi.org/10.3389/fmicb.2019.02266

Mazumdar, M.D. and Goswami, J.S. (2016). Impact of training of street food vendors on food safety and hygiene practices in the city of Guwahati. International Journal of Multidisciplinary Research Review, 1(3), 37-40.

National Centre for Disease Control. (2017). Directorate General of Health Services, Government of India. CD Alert. Food-Borne Diseases and Food Safety in India. Monthly Newsletter. Retrieved from National Centre for disease Control, Directorate General of Health Services, Government of India website: https://ncdc.gov.in/WriteReadData/linkimages/CD\% 20Alert4053017156.pdf

Newell, D.G., Koopmans, M., Verhoef, L., Duizer, E., Aidara-Kane, A., Sprong, H., Opsteegh, M., Langelaar, M., Threfall, J., Scheutz, F., van der Giessen, J. and Kruse, H. (2010). Food-borne diseases - The challenges of 20 years ago still persist while new ones continue to emerge. International Journal of Food Microbiology,139 (Suppl. 1), S3-S15.https://doi.org/10.1016/ j.ijfoodmicro.2010.01.021

Nyenje, M.E., Odjadjare, C.E., Tanih, N.F., Green E. and Ndip, R.N. (2012). Foodborne Pathogens Recovered from Ready-to-Eat Foods from Roadside Cafeterias and Retail Outlets in Alice, Eastern Cape Province, South Africa: Public Health Implications. International Journal of Environmental Research and Public Health, 9(8), 2608-2619. https:// doi.org/10.3390/ijerph9082608

Odeyemi, O.A. (2016). Public health implications of microbial food safety and foodborne diseases in developing countries. Food and Nutrition Research, 
60, 29819. https://doi.org/10.3402/fnr.v60.29819

Okareh, O.T. and Erhahon, O.O. (2015). Microbiological Assessment of Food and Hand-Swabs Samples of School Food Vendors in Benin City, Nigeria. Food and Public Health, 5(1), 23-28.

Pal, M. (2014). Spoilage of Dairy Products due to Fungi. Beverage and Food World, 41(7), 37-38.

Parry, N. (2018). Food poisoning is the second most common infectious outbreak in India. Retrieved from website: https:// www.healthissuesindia.com/2018/03/27/foodpoisoning-is-the-second-most-common-infectiousoutbreak-in-india/.

Pigott, D.C. (2008). Foodborne Illness. Emergency Medicine Clinics of North America, 26(2), 475-497. https://doi.org/10.1016/j.emc.2008.01.009

Pires, S.M., Evers, E.G., van Pelt, W., Ayers, T., Scallan, E., Angulo, F.J., Havelaar, A. and Hald, T. (2009). Attributing the human disease burden of foodborne infections to specific sources. Foodborne Pathogens and Disease, 6(4), 417-424.https://doi.org/10.1089/ fpd.2008.0208

Pitt, J.I. (2000). Toxigenic fungi: which are important.? Medical Mycology, 38(Supp. 1), 17-22. https:// doi.org/10.1080/mmy.38.s1.17.22

Podolak, R., Enache, E., Stone, W., Black, D.G. and Elliott, P.H. (2010). Sources and Risk Factors for Contamination, Survival, Persistence, and Heat Resistance of Salmonella in Low-Moisture Foods. Journal of Food Protection, 73(10), 19191936.https://doi.org/10.4315/0362-028X-73.10.1919

Russell, R., Paterson, M. and Lima, N. (2017). Filamentous Fungal Human Pathogens from Food Emphasising Aspergillus, Fusarium and Mucor. Microorganisms, 5(44), 1-9. https://doi.org/10.3390/ microorganisms 5030044

Sabbithi, A., Kumar, R.N., Kashinath, L., Bhaskar, V. and Rao, V.S. (2014). Microbiological Quality of Salads Served along with Street Foods of Hyderabad, India. International Journal of Microbiology, 2014, 932191. https:// doi.org/10.1155/2014/932191

Saravanan, A.V., Sibyl, S., Bennadi, D. and Kshetrimayum, N. (2016). Food Safety among Food Vendors in Chennai City-A Cross Sectional Survey. International Journal of Pharma Research and Health Sciences, 4(6), 1466-1469.

Schlundt, J. (2002). New directions in foodborne disease prevention. International Journal of Food Microbiology, 78(1-2), 3 - 17.https:// doi.org/10.1016/S0168-1605(02)00234-9

Scott, E. (2003). Food safety and foodborne disease in 21st century homes. Canadian Journal of Infectious Diseases, 14(5),277-280. https:// doi.org/10.1155/2003/363984

Sehgal, R., Kumar, Y. and Kumar, S. (2008). Prevalence and geographical distribution of Escherichia coli O157 in India: a 10-year survey. Transactions of the Royal Society of Tropical Medicine and Hygiene, 102(4), 380-383. https://doi.org/10.1016/ j.trstmh.2008.01.015

Simjee, S. (2007). Foodborne Diseases, p. 1-511. New Jersey, USA: Humana Press Inc. https:// doi.org/10.1007/978-1-59745-501-5

Singh, A.K., Dudeja, P., Kaushal, N. and Mukherji, S. (2016). Impact of health education intervention on food safety and hygiene of street vendors: A pilot study. Medical Journal Armed Forces India, 72(3), 265-269. https://doi.org/10.1016/j.mjafi.2016.02.008

Singh, A.K., Singh N.P. and Chaturvedani, A.K. (2018). Food Safety and Hygiene Practices among Street Food Vendors in Noida, Uttar Pradesh, India. International Journal of Current Microbiology and Applied Sciences, 7(9), 2340-2347. https:// doi.org/10.20546/ijcmas.2018.709.291

Sudershan, R.V., Kumar, R.N., Kashinath, L., Bhaskar, V. and Polasa, K. (2014). Foodborne Infections and Intoxications in Hyderabad India. Epidemiology Research International, 2014, 942961. https:// doi.org/10.1155/2014/942961

Sudershan, R.V., Rao, G.M.S., Rao, P., Rao, M.V.V. and Polasa, K. (2008). Food safety related perceptions and practices of mothers - A case study in Hyderabad, India. Food Control, 19(5), 506513.https://doi.org/10.1016/j.foodcont.2007.05.017

Tambekar, D.H., Jaiswal, V.J., Dhanorkar, D.V., Gulhane, P.B. and Dudhane, M.N. (2008). Identification of microbiological hazards and safety of ready-to-eat food vended in streets of Amravati City, India. Journal of Applied Biosciences, 7, 195 201.

Tauxe, R.V. (1997). Emerging Foodborne Diseases: An Evolving Public Health Challenge. Emerging Infectious Diseases, 3(4), 425-434.https:// doi.org/10.3201/eid0304.970403

Thakur, C.P., Mehra, R., Narula, C., Mahapatra S. and Kalita, T.J. (2013). Food safety and hygiene practices among street food vendors in Delhi, India. International Journal of Current Research, 5(11), 3531-3534.

Times of India. (2019). Study: Food-borne diseases cost India \$15 billion a year - 27th February 2019. Retrieved from website: https:// timesofindia.indiatimes.com/india/study-food-borne- 
diseases-cost-india-15-billion-a-year/

articleshow/68176718.cms.

Urmimala, B. and Sukanya, G. (2017). Hygienic Practices of Food Handlers in India. International Journal of Food, Nutrition and Dietetics, 5(3), 6165.

Van de Venter, T. (2000). Emerging food-borne diseases: a global responsibility. Food, Agriculture and Nutrition, 26, 4-13. Retrieved from FAO website: https://www.fao.org/3/x7133m/ x7133m01.pdf

Vemula, S.R., Kumar, R.N. and Polasa, K. (2012). Foodborne diseases in India - a review. British Food Journal, $114(5), \quad 661 \quad-\quad 680 . h t t p s: / /$ doi.org/10.1108/00070701211229954

Vyas, M. and Pandya, C. (2019). An Outbreak of Staphylococcal Food Poisoning Occurs at Low Literacy Girl High School Rajpipala, Narmada District. National Journal of Community Medicine, 10(5), 304-307.

World Health Organization. (2015a). Foodborne diseases in the WHO South-East Asia Region. Retrieved from WHO website: https://apps.who.int/iris/ handle/10665/327655

World Health Organization. (2015b). WHO estimates of the global burden of foodborne diseases, foodborne disease burden epidemiology reference group 20072015. Retrieved from WHO website: https:// apps.who.int/iris/handle/10665/199350

Wu, F., Groopman, J.D. and Pestka, J.J. (2014). Public Health Impacts of Foodborne Mycotoxins. Annual Review of Food Science and Technology, 5, 351372. https://doi.org/10.1146/annurev-food-030713092431

Zahoor, T., Azhar, N., Salik, A. and Liaqat, A. (2018). Prevalence of pathogenic bacteria in traditional foods of Pakistan: A scenario of underdeveloped countries. Journal of Food Microbiology, Safety and Hygiene, 3, 59. https://doi.org/10.4172/2476-2059$\mathrm{C} 2-012$

Zheng, G. and Shen, Z. (2018). Host-specific Genetic Markers of Faecal Bacteria for Faecal Source Tracking in Food and Water. Journal of Food Microbiology, Safety and Hygiene, 3(1), 1000135. https://doi.org/10.4172/2476-2059.1000135

Zweifel, C. and Stephan, R. (2012). Spices and herbs as source of Salmonella-related foodborne diseases. Food Research International, 45(2), 765-769. https://doi.org/10.1016/j.foodres.2011.02.024 